\title{
Single-Stage Isolated Electrolytic Capacitor-Less EV Onboard Charger With Power Decoupling
}

\author{
Ali Tausif, Hoyoung Jung, and Sewan Choi
}

\begin{abstract}
In this paper, a new single-stage single-phase isolated AC-DC converter derived from a differential boost AC-DC converter is proposed. This converter eliminates the need to use the bulky electrolytic capacitor from the system and at the same time provides DC charging by employing the AC Power Decoupling waveform control method, effectively addressing the power density and reliability related issues commonly associated with the bulky electrolytic capacitor. As half of the switches of this converter act as synchronous rectifier during half grid cycle they are inherently ZVS Turned On while the remaining switches achieve ZVS Turn On as they act as synchronous rectifier during other half grid cycle. However, all diodes at the secondary side achieve ZCS Turn Off during the entire line cycle. A conventional controller is implemented for output voltage regulation and PFC control whereas a power decoupling controller is added to compensate second harmonic ripple power. Besides, an interleaving technique is applied to provide high-frequency links for transformers' connection while at the same time increasing the power range and effectively reducing the size of the input filter. Finally, the operating principle of the converter is validated through simulation, and the experimental results are provided.
\end{abstract}

Index Terms - Current-fed isolated AC-DC, differential converter, electrolytic capacitor-less, onboard battery charger, power decoupling, single-stage system.

\section{INTRODUCTION}

$\mathrm{T}$ HE onboard battery chargers (OBCs) are crucial power electronic components in plug-in hybrid electric vehicles (PHEV) and battery electric vehicles (BEV) as they receive power from the grid, convert it to suitable DC voltage, and charges vehicle's battery. Introduction to wideband gap devices such as $\mathrm{SiC}$ and $\mathrm{GaN}$ in the automotive sector has already revolutionized the electric vehicles power electronics as these devices can operate at high switching frequency with minimal switching and conduction losses which have greatly enhanced the efficiency and power density requirement of the system [1]-[3]. Since OBCs are installed inside vehicles, therefore it is mandatory to develop a charger that should be compact, highly

Manuscript received January 27, 2019. This work was supported by "Human Resources Development of Korea Institute of Energy Technology Evaluation and Planning (KETEP), grant funded by the Korea Government Ministry of Trade, Industry \& Energy (No. 20174030201840). This paper was presented in part at the 2018 IEEE International Power Electronics and Application Conference and Exposition (PEAC), Shenzhen, China, November 2018.

All authors are with the Department of Electrical and Information Engineering, Seoul National University of Science and Technology, 418, Mirae hall 232 Gongneung-ro, Nowon-gu 01811, the Republic of Korea (ROK) (e-mail: ali. tausif@seoultech.ac.kr).

Digital Object Identifier 10.24295/CPSSTPEA.2019.00004 efficient and reliable. According to DOE technical targets 2022, OBC should have an efficiency above $94 \%$ and a power density higher than $0.943 \mathrm{~kW} / \mathrm{L}$ [4]. Much research is going on in developing new topologies that are reliable and can address the issues of the existing topologies cost-effectively.

A conventional approach for $\mathrm{EV} \mathrm{OBC}$ is a two-stage structure which consists of a front end AC-DC boost PFC converter followed by an isolated DC-DC converter for output regulation [5]. The main advantage of this $\mathrm{OBC}$ is its simple structure and control implementation whereas the downside of this is its low efficiency because of its hard switched front end AC-DC converter and due to the existence of diode bridge at grid side it experiences high conduction loss. Besides, a large electrolytic capacitor is used as the DC link capacitor to smooth out the DC voltage which reduces the power density and lifetime of the converter.

Another variation of this topology is to use interleaved boost PFC as an AC-DC converter and full-bridge phase shift converter as a DC-DC converter [6]. The significant improvement is the reduction of switch current rating as the current is divided into half due to interleaving.

It must be noted that in the two-stage topologies explained above, the conduction loss due to slow diode bridge is very significant. To minimize this loss, a bridgeless AC-DC converter is employed as a front end PFC stage followed by DC-DC fullbridge converter [7]. This converter significantly minimizes the conduction losses associated with the diode bridge. However, this bridgeless AC-DC converter is hard switched in nature which limits the increase in switching frequency. Moreover, the capacitance requirement for DC link capacitor is usually high as 2nd harmonic ripple associated with the single-phase system needs to be absorbed to get smooth DC current. So, a bulky electrolytic capacitor is a must which affects the lifetime and power density of the converter.

A reasonable method is also proposed in [7] which solves this constraint of using electrolytic capacitor by replacing it with a film capacitor and allowing 2 nd harmonic voltage swing in the DC link capacitor voltage. However, due to this voltage swing, the voltage rating of the switches is increased. Moreover, switching loss associated with AC-DC bridgeless converter still poses restriction in using high frequency and affects efficiency.

Currently, single-stage EV chargers are quite attractive and hot topic for the research. The advantages of single-stage topologies are low components count, high efficiency and compactness.

One single-stage topology is proposed in [8]. It is a three 
level isolated AC-DC converter. In this topology, a bulky electrolytic capacitor is employed as a DC link capacitor which compromises the volume of the circuit. Moreover, the low-frequency component exists in the transformer winding voltage that increases the size of the transformer. This issue is resolved in [9] in which electrolytic capacitor is replaced by film capacitor; however, it still experiences high conduction loss due to slow diode bridge and also it charges the battery with the sinusoidal current which has a detrimental effect of battery's lifetime due to the heating issue.

Two similar but bridgeless and electrolytic capacitor-less topologies are proposed in [10], [11]. These topologies address most of the issues related to single-stage topologies such as a lowfrequency component in transformer voltage, high conduction loss in diode bridge and unreliability due to the short life span of electrolytic capacitors. However, the topology in [11] is superior to [10] concerning its simple structure, bi-directional ability and wide range soft switching capability. The disadvantage with these topologies is the undesirable 2nd harmonic ripple in the battery current which heats the battery and eventually affects its lifetime.

To resolve 2nd harmonic ripple problem associated with single-phase systems many power decoupling techniques have been reviewed and reported in [12], [13]. These techniques have been classified into 2 major categories: 1) independent power decoupling, 2) dependent power decoupling.

In independent power decoupling, the power decoupling cells operate independently from the main converter. Therefore, it requires additional switches to carry out power decoupling which results in increased gate driver losses and circuit complexity. Few well-known topologies for independent power decoupling are proposed in [14]-[18].

On the other hand, the dependent power decoupling method is a convenient way for 2 nd harmonic ripple mitigation, as basic decoupling cell shares power semiconductor devices with the original converter partially or even fully. Some of the power decoupling methods in which semiconductor devices are partially shared between power decoupling cell and original converter are proposed in [19]-[21]. Decoupling methods which fully shares the switches with the main converter are also categorised as AC power decoupling methods. In AC power decoupling method, 2nd ripple power is diverted from the DC link and is stored in decoupling capacitors [23]-[25].

One of the suitable AC power decoupling control methods is proposed for the non-isolated AC-DC converter in [26], [27] and is applied to the non-isolated AC-DC differential boost converter [28]. In this approach, power decoupling is successfully achieved by using autonomous closed loop controller. Hence, this concept is extended to obtain a new isolated AC-DC converter which is suitable for $\mathrm{EV}$ onboard battery chargers.

The proposed converter has the following features: 1) electrolytic capacitor-less system, 2) high-frequency isolation, 3) AC Power Decoupling and 4) interleaving technique: suitable for high power applications.

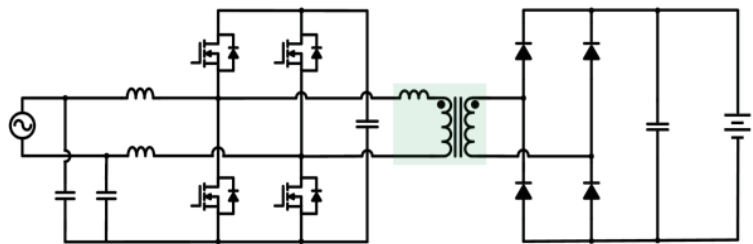

(a)

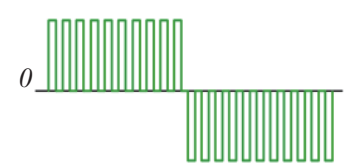

(b)

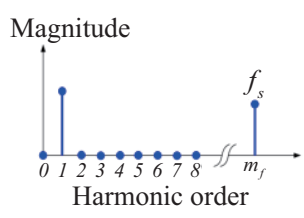

(c)
Fig. 1. Single-stage differential boost-type isolated AC-DC converter. (a) Topology. (b) Transformer winding voltage. (c) FFT of transformer winding voltage.

\section{Proposed Converter}

\section{A. Topology Development}

A single stage isolated AC-DC converter based on a differential converter [26] can be constructed as shown in Fig. 1(a). A power decoupling method [23] for a differential converter can be applied to the single stage isolated AC-DC converter. However, the fundamental frequency component appears in the transformer winding voltage as shown in Fig. 1(b) and (c). This fundamental frequency component results in low frequency component in the magnetizing current. Therefore it increases the volume requirement of the transformer making the converter impractical.

In order to have high frequency isolation, the proposed converter, as shown in Fig. 2, is derived by interleaving each leg of the differential converter [26] and connecting each interleaved leg to the transformer windings of two isolated AC-DC converters [29]. Therefore, the two phase interleaved legs have a $180^{\circ}$ phase shift in switching frequency. Since there are two of such high frequency links, two transformers are fully utilized and the power is shared between the two converters.

\section{B. Voltage Conversion Ratio}

As illustrated in Fig. 3, the proposed converter is composed of two boost converters in which duty $d_{1}$ is given to converter 1 , and duty $d_{2}$ is given to converter 2 . Therefore, the voltage conversion ratio of each boost converter is as shown below (1) and (2).

$$
\begin{aligned}
& \frac{v_{c 1}}{1-d_{1}}=v_{c c} \\
& \frac{v_{c 2}}{1-d_{2}}=v_{c c} \\
& v_{g}=v_{c 1}-v_{c 2}
\end{aligned}
$$

Substituting (1) and (2) in (3) yields,

$$
v_{g}=\left(d_{2}-d_{1}\right) v_{c c}=\left(d_{2}-d_{1}\right) n \cdot v_{b a t}
$$




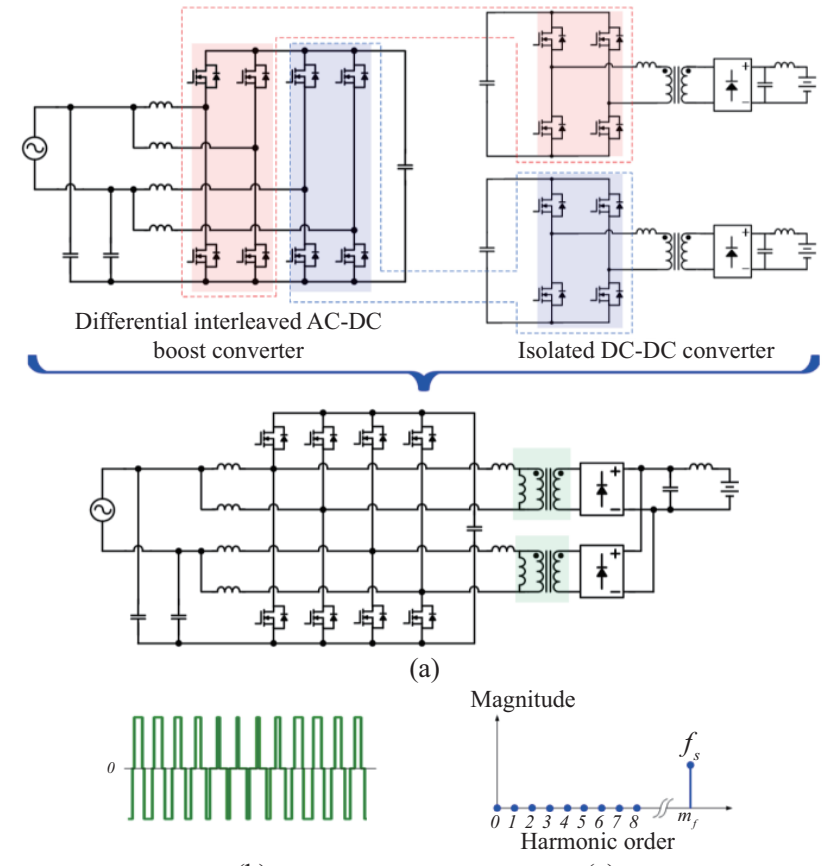

(b)

(c)

Fig. 2. Proposed single-stage interleaved isolated AC-DC converter. (a) Concept of developing the topology. (b) Transformer winding voltage. (c) FFT of transformer winding voltage.

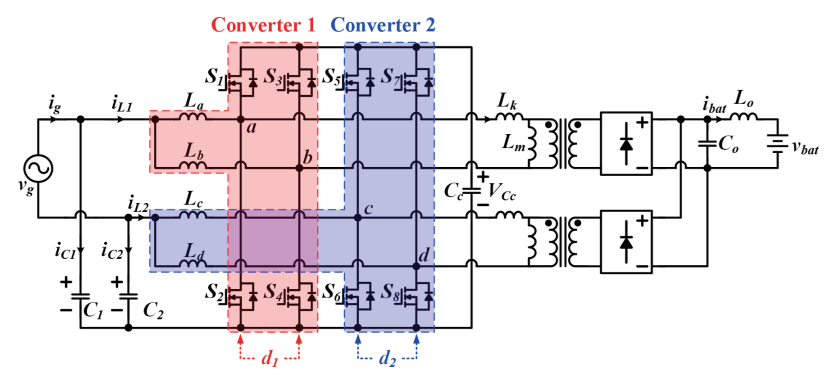

Fig. 3. The structure of the proposed converter.

So, voltage conversion ratio of this topology is,

$$
M=\frac{v_{b a t}}{v_{g}}=\frac{1}{n\left(d_{2}-d_{1}\right)}
$$

\section{Topology Description}

The proposed converter is shown in Fig. 3. It consists of 8 switches at primary side namely $S_{1} \sim S_{8}$. At input side there are two capacitors $C_{1}$ and $C_{2}$ followed by input inductors $L_{\mathrm{a}}, L_{\mathrm{b}}$, $L_{\mathrm{c}}$ and $L_{\mathrm{d}}$. Two transformers $T_{1}$ and $T_{2}$ are connected between interleaved legs formed by $\operatorname{leg} a, \operatorname{leg} b, \operatorname{leg} c$, and $\operatorname{leg} d$ respectively. The secondary side consists of two full bridge diode rectifiers which are connected in parallel and serve as the output terminal. $C_{c}$ is the clamping capacitor and voltage across $C_{c}$ is equal to the battery voltage reflected to the primary side, i.e., if leakage inductance of the transformer is assumed to be negligible, then $V_{C c}=n \cdot v_{b a t}$.

According to differential converter [26] concept voltage across $C_{1}$ and $C_{2}$ is given as:

$$
\begin{aligned}
& v_{c 1}=\frac{n v_{b a t}}{2}+\frac{V_{g}}{2} \sin \omega t \\
& v_{c 2}=\frac{n v_{b a t}}{2}-\frac{V_{g}}{2} \sin \omega t
\end{aligned}
$$

It can be seen that grid voltage and current is given as:

$$
\begin{gathered}
v_{g}=v_{c 1}-v_{c 2}=V_{g} \sin \omega t \\
i_{g}=I_{g} \sin (\omega t+\delta)
\end{gathered}
$$

In the proposed topology $C_{1}$ and $C_{2}$ are connected directly to the grid. Therefore, leading current will flow through $C_{1}$ and $C_{2}$ which is given by,

$$
i_{\text {lead }}=C_{e q} \frac{d v_{g}}{d t}
$$

where $C_{e q}=C_{1} \| C_{2}$ and $C_{1}, C_{2}=C$.

$$
i_{\text {lead }}=\frac{\omega C V_{g}}{2} \cos \omega t
$$

Note that this leading current depends upon the value of $C_{1}$ and $C_{2}$ and it introduces a slight phase shift $(\delta)$ in the grid current deteriorating the power factor. Hence, there will be some reactive power flow into the circuit. However, this current can be minimized by adding reactive power compensation in the controller of the proposed converter.

The instantaneous power flowing across $C_{1}$ and $C_{2}$ is given as:

$$
\begin{gathered}
p_{c}=v_{c 1} C_{1} \frac{d v_{c 1}}{d t}+v_{c 2} C_{2} \frac{d v_{c 2}}{d t} \\
p_{c}=\frac{\omega C V_{g}}{4} \sin 2 \omega t
\end{gathered}
$$

Equation (13) is equivalent to reactive power due to leading current.

\section{Principle of Power Decoupling}

In single phase, AC-DC systems power pulsation at double the line frequency occurs and it is unavoidable in the case of using film capacitors. This 2 nd harmonic ripple power appears at the output in the form of pulsating battery current.

Assuming $\mathrm{PF}=1$, power at the grid side can be calculated as:

$$
\begin{gathered}
p_{\text {in }}=v_{g} \cdot i_{g} \\
p_{\text {in }}=\frac{V_{g} I_{g}}{2}-\frac{V_{g} I_{g} \cos 2 \omega t}{2}
\end{gathered}
$$

Since, output power is equal to the input power, assuming the converter to be lossless.

$$
p_{\text {out }}=\frac{V_{g} I_{g}}{2}-\frac{V_{g} I_{g} \cos 2 \omega t}{2}
$$

From (16), the instantaneous output power comprises of average power and undesirable ripple power. In the proposed 


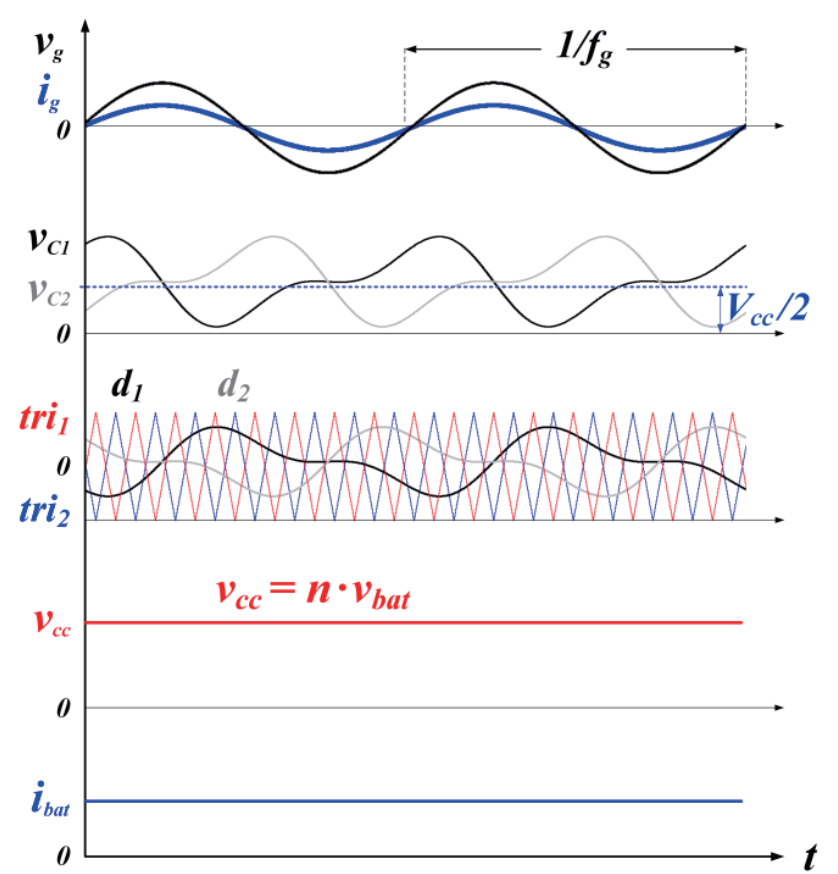

Fig. 4. Key waveform of operating principle for grid frequency.

converter this ripple power is decoupled from the output and is stored in the input capacitors $C_{1}$ and $C_{2}$ as 2 nd harmonic voltage component illustrated in Fig. 4. This is accomplished by shaping the voltage across $C_{1}$ and $C_{2}$ as:

$$
\begin{aligned}
& v_{c 1}=\frac{n v_{b a t}}{2}+\frac{V_{g}}{2} \sin \omega t+V_{c} \sin (2 \omega t+\phi) \\
& v_{c 2}=\frac{n v_{b a t}}{2}-\frac{V_{g}}{2} \sin \omega t+V_{c} \sin (2 \omega t+\phi)
\end{aligned}
$$

During power decoupling operation, the ripple power component in (16) is diverted from output to $C_{1}$ and $C_{2}$, so the instantaneous power across $C_{1}$ and $C_{2}$ can be obtained by substituting (17) and (18) in (12),

$$
\begin{aligned}
p_{c}= & \frac{V_{g}^{2}}{4} \omega C \sin 2 \omega t+2 n v_{b a t} V_{c} \omega C \cos (2 \omega t+\phi) \\
& +4 \omega C V_{c}^{2} \sin (4 \omega t+2 \phi)
\end{aligned}
$$

Note that (19) contains 2nd and 4th harmonic component, this 4th harmonic ripple component is usually small and it can be neglected, so 2nd harmonic component in (19) equates to ripple power component in (16) given as,

$$
\begin{array}{r}
\frac{V_{g}^{2}}{4} \omega C \sin 2 \omega t+2 n v_{b a t} V_{c} \omega C \cos (2 \omega t+\phi) \\
=\frac{V_{g} I_{g} \cos 2 \omega t}{2}
\end{array}
$$

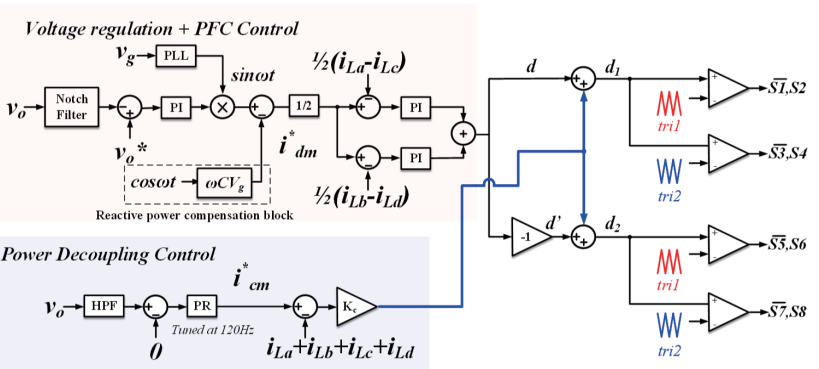

Fig. 5. Block diagram of the proposed controller.

$$
\begin{gathered}
V_{c}=\frac{V_{g} \sqrt{V_{g}^{2} \omega^{2} C^{2}+4 I_{g}^{2}}}{8 n v_{b a t} C \omega} \\
\phi=\pi-\tan ^{-1} \frac{V_{g} \omega C}{2 I_{g}}
\end{gathered}
$$

Substituting $V_{c}$ and $\phi$ in (17) and (18) yields,

$$
\begin{aligned}
v_{c 1}= & \frac{n v_{b a t}}{2}+\frac{V_{g}}{2} \sin \omega t-\frac{P_{O}}{2 n v_{b a t}} \cos 2 \omega t \\
& +\frac{V_{g}^{2}}{8 n v_{b a t}} \cos 2 \omega t \\
v_{c 2}= & \frac{n v_{b a t}}{2}-\frac{V_{g}}{2} \sin \omega t-\frac{P_{O}}{2 n v_{b a t}} \cos 2 \omega t \\
& +\frac{V_{g}^{2}}{8 n v_{b a t}} \cos 2 \omega t
\end{aligned}
$$

It can be seen that for a fixed grid voltage, $V_{c}$ and $\phi$ are load dependent parameters and in the proposed converter, $V_{c}$ and $\phi$ are adjusted by closed-loop controller.

\section{Control Method}

The controller for the proposed topology is divided into two parts: the differential mode controller and the common mode controller. The differential mode controller is responsible for PFC control and output voltage regulation. In this controller, the difference of sensed inductor currents is compared with the reference to generate an error which is compensated by the inner current loop PI controller. Due to interleaving and nonlinear duty, the inductor current imbalance problem may occur, but it can be resolved by dividing the reference into half and using two separate controllers for each interleaving legs as shown in Fig. 5. Apart from this, a reactive power due to leading current is compensated by adding a feed forward term in the reference of the differential current. The value of this compensating signal is fixed for a particular grid voltage and is independent of load as can be seen from (11).

The reference for differential mode current is given as:

$$
i_{d m}^{*}=\frac{\left(i_{L a}+i_{L b}\right)-\left(i_{L c}+i_{L d}\right)}{2}=i_{g}^{*}-i_{\text {lead }}^{*}
$$

In addition to this, Common Mode Power Decoupling Con- 


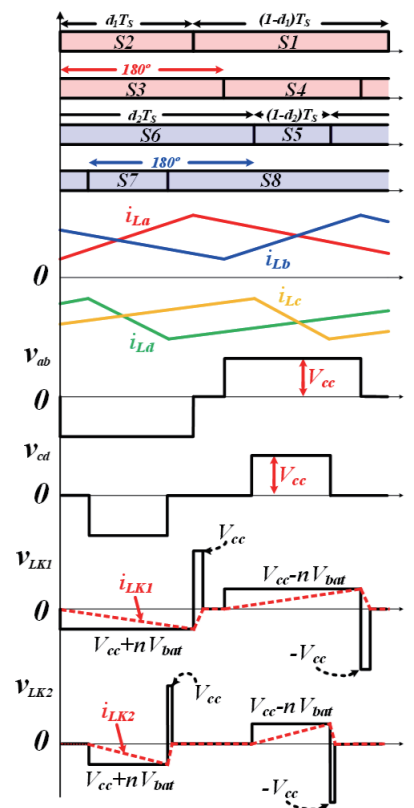

(a)

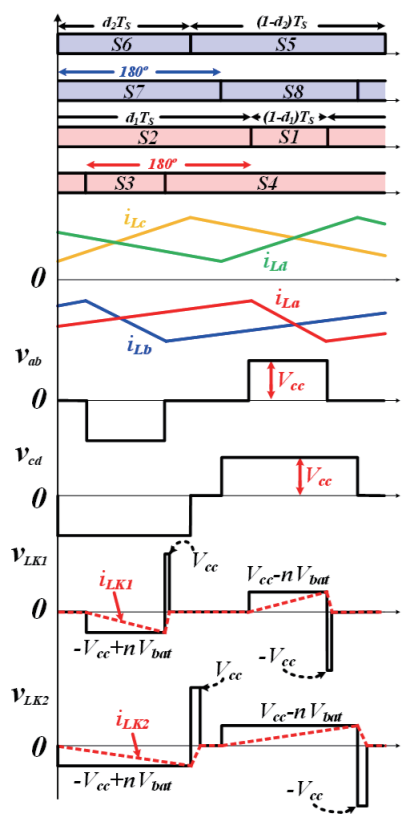

(b)
Fig. 6. Key waveforms of the converter for switching period, (a) when $v_{g}>0$, (b) when $v_{g}<0$.

trol is applied in which 2nd harmonic ripple is extracted from output and is subtracted from 0 reference to generate an error. This error is minimized by using the PR controller tuned at $120 \mathrm{~Hz}$ and the 2nd harmonic compensated signal is generated.

The reference for common mode current is given as:

$$
\begin{aligned}
i_{c m}^{*} & =i_{L a}+i_{L b}+i_{L c}+i_{L d}=2 C \frac{d}{d t}\left(v_{c m}\right) \\
& =2 C \frac{d}{d t}\left(\frac{v_{c 1}+v_{c 2}}{2}\right) \\
& =4 \omega C V_{c} \cos (2 \omega t+\phi)
\end{aligned}
$$

The compensated signal is the reference signal and it is compared with the sum of all sensed inductor currents. The resulted signal is then fed to the proportional controller with gain $\mathrm{K}_{\mathrm{c}}$ which is added to the differential mode controller duties $d$ and $d^{\prime}$ to obtain final duties $d_{1}$ and $d_{2}$.

\section{Operating Principles}

The primary side of the converter can be thought of as two interleaved converters are illustrated in Fig. 2. One converter in composed of $S_{1}, S_{2}, S_{3}$ and $S_{4}$ is operated with duty $d_{1}$ while the other converter is composed of $S_{5}, S_{6}, S_{7}$ and $S_{8}$ is operated with duty $d_{2}$. During positive half cycle converter 1 acts as an interleaved boost converter whereas converter 2 acts as an interleaved buck converter. Similarly, during negative half cycle converter 2 acts as interleaved buck converter and converter 1 acts as interleaved boost. The key waveforms of the converter are shown in Fig. 6.

\section{A. Modes by Mode Operation}

During the positive half cycle of the grid, the proposed converter undergoes five distinct modes of operation based on its switching status. During Mode 1 switches $S_{2}, S_{3}, S_{6}$ and $S_{8}$ are ON, and switches $S_{1}, S_{4}, S_{5}$ and $S_{7}$ are turned OFF. Inductor $L_{\mathrm{a}}$ charges and $L_{\mathrm{b}}$ discharges. However, both $L_{\mathrm{c}}$ and $L_{\mathrm{d}}$ discharge as these inductors are associated with converter 2 which acts as the buck converter during this mode. In this mode $v_{a b}=-V_{C c}$ and the power is transferred to the battery through transformer $T_{1}$. The current through the transformer increases with the slope given as:

$$
\frac{d i_{L k 1}}{d t}=\frac{-V_{C c}+n V_{b a t}}{L_{k}}
$$

Mode 2 starts when $S_{7}$ is turned $\mathrm{ON}$ and $S_{6}$ is turned $\mathrm{OFF}$, as shown in Fig. 7. The status of the switches of converters is given as $S_{2}, S_{3}, S_{6}$ and $S_{7}$ are ON while all other switches are OFF. Since $S_{7}$ is turned ON the inductor $L_{\mathrm{d}}$ begins to charge in this mode. During this mode the slopes of other inductor currents remain same, however $v_{c d}=-V_{C c}$, therefore power is transferred through the transformer $T_{2}$ as well. The slope of $i_{L k 2}$ is given as:

$$
\frac{d i_{L k 2}}{d t}=\frac{-V_{C_{c}}+n V_{b a t}}{L_{k 2}}
$$

As shown in Fig. 7, during Mode 3, $S_{1}, S_{3}, S_{6}$ and $S_{8}$ are ON while others are OFF. Inductor $L_{a}$ and $L_{b}$ discharge through the clamping capacitor $C_{c}$ while $L_{c}$ and $L_{d}$ discharge through decoupling capacitor $C_{2}$. During this mode, $v_{a b}, v_{c d}=0$, therefore no power is transferred in this mode.

Mode 4 begins when $S_{4}$ is turned $\mathrm{ON}$ and $S_{3}$ is turned OFF. During this mode $L_{b}$ begins to charge while all the other inductors are still discharging as in the previous mode. However, during this mode, $v_{a b}=V_{C c}$, therefore power is being transferred to the load only through the transformer $T_{1}$ and its current increases with the slope given as:

$$
\frac{d i_{L k 1}}{d t}=\frac{V_{C c}-n V_{b a t}}{L_{k 1}}
$$

Similarly, during Mode 5, $S_{5}$ is turned ON, and $S_{6}$ is turned OFF. During this mode, $L_{c}$ begins to discharge as a negative voltage equal to $-v_{c 2}$ is applied across it. In this mode, $v_{a b}=V_{C c}$, therefore the commutation occurs through both the transformers $T_{1}$ and $T_{2}$ and power is being transferred to the load. The slopes of current through leakage inductances of transformers $T_{2}$ is given as:

$$
\frac{d i_{L k 2}}{d t}=\frac{V_{C c}-n V_{b a t}}{L_{k 2}}
$$

Operation during the negative half cycle is similar to the positive half cycle. The only difference is that during negative half cycle converter 1 acts as interleaved buck while converter 2 acts as an interleaved boost converter. Operating waveform of the converter for switching period and $v_{g}<0$ is presented in Fig. 6(b). 


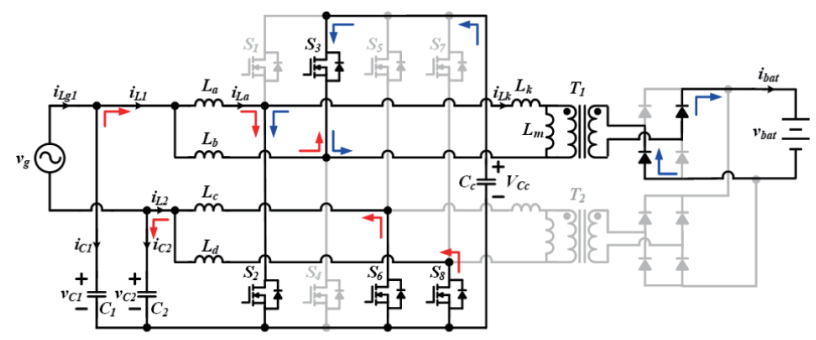

Mode 1

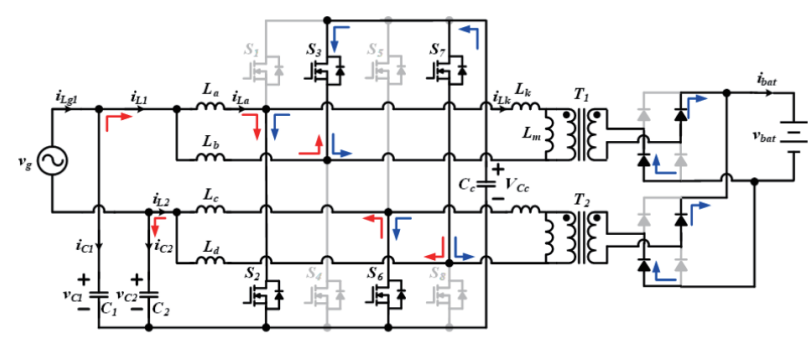

Mode 2

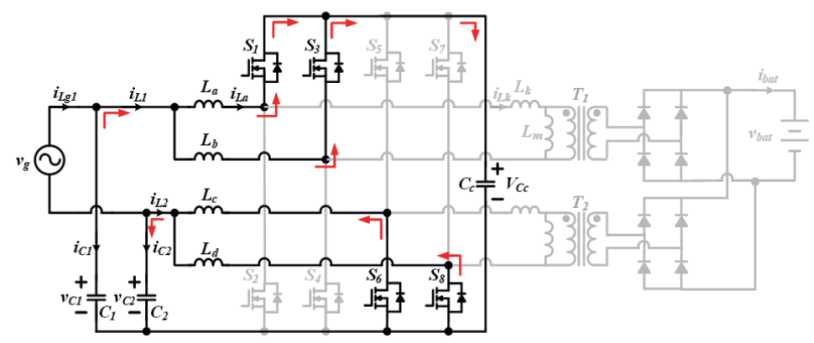

Mode 3

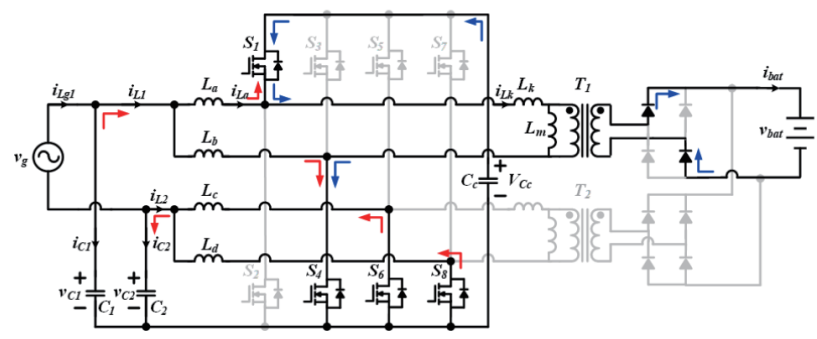

Mode 4

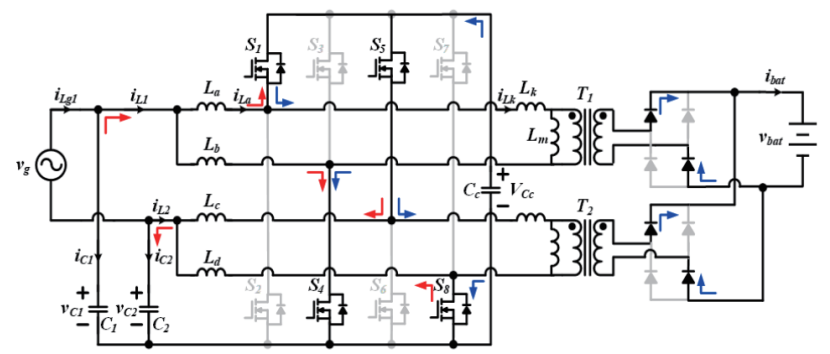

Mode 5

Fig. 7. Modes by mode operation $v_{g}>0$.

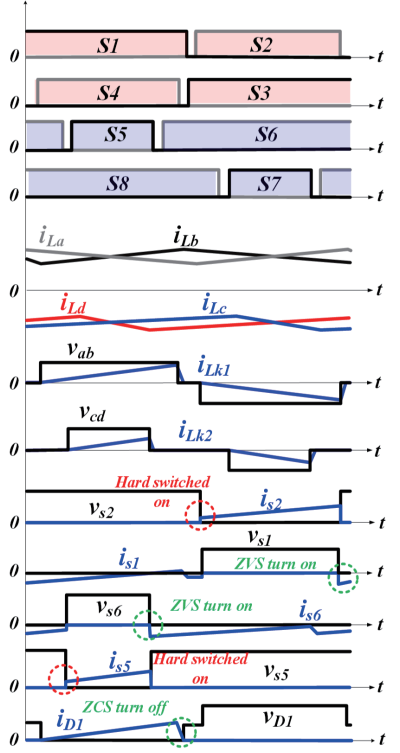

(a)

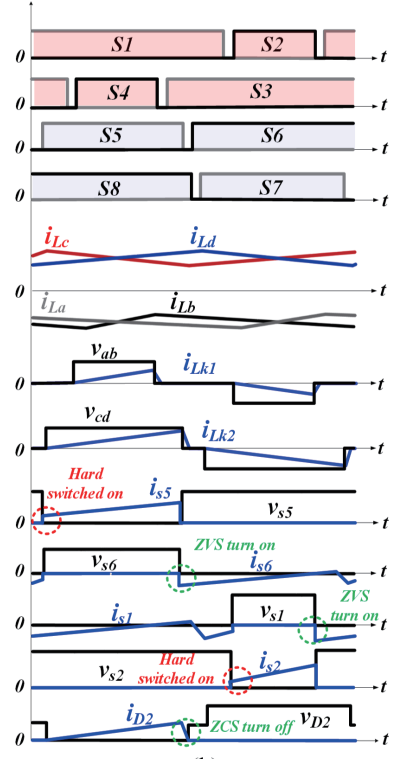

(b)
Fig. 8. Switching characteristics, (a) when $v_{g}>0$, (b) when $v_{g}<0$.

\section{B. Switching Characteristics}

As already explained in the previous section, during the positive half cycle, the operation of converter 1 is similar to the interleaved boost converter and that of converter 2 is similar to the interleaved buck converter. Therefore, the switches $S_{1}$ and $S_{3}$ associated with converter 1 act as synchronous rectifiers and are always turned on with ZVS condition. Whereas switches $S_{2}$ and $S_{4}$ are hard switched as illustrated in Fig. 8(a). Similarly, switches $S_{6}$ and $S_{8}$ act as synchronous rectifiers of the interleaved buck converter, i.e., converter 2 and they always achieve ZVS Turn ON, while $S_{5}$ and $S_{7}$ are hard turned ON.

The operation of converter 1 during the negative half cycle is similar to that of the positive half cycle with the only difference that converter 1 acts as the interleaved buck converter and converter 2 acts as the interleaved boost converter. Therefore switches $S_{2}, S_{4}, S_{5}$ and $S_{7}$ turn ON with ZVS condition and remaining switches are hard turned ON. The waveform of this phenomenon is presented in Fig. 8(b).

Note that all diodes at the secondary side turn OFF with ZCS, the currents flowing through the diodes are the leakage inductor currents $i_{L k 1}$ and $i_{L k 2}$ reflected to the secondary side. Since, $L_{k l}$ and $L_{k 2}$ are always naturally clamped to $V_{C c}$, hence all secondary diodes turn OFF with slopes given as $\frac{V_{C c}}{L_{k}}$.

\section{Simulation and Experimental Results}

The simulation of the proposed converter is performed in PSIM and circuit components are selected based on $6.6 \mathrm{~kW}$ design. Table I shows the circuit parameters.

The universal input range of $90 \sim 250 \mathrm{~V}_{\mathrm{rms}}$ is considered for the design. For typical onboard battery chargers, the output voltage range is from $250 \sim 450 \mathrm{~V}$. Input inductor are selected based on input current $T H D_{i g}$ which is kept around 5\% for the 
TABLE I

Circuit Parameters

\begin{tabular}{lcc}
\hline \hline Output power & $P_{o}$ & $6.6 \mathrm{~kW}$ \\
Switching frequency & $f_{s}$ & $200 \mathrm{kHz}$ \\
Grid voltage & $V_{g}$ & $220 \mathrm{~V}_{\mathrm{rms}}$ \\
Output voltage & $V_{o}$ & $450 \mathrm{~V}$ \\
Input inductors & $L_{a}, L_{b}, L_{c}, L_{d}$ & $60 \mu \mathrm{H}$ \\
Decoupling capacitors & $C_{l}, C_{2}$ & $100 \mu \mathrm{F}$ \\
Clamping capacitor & $C_{c}$ & $40 \mu \mathrm{F}$ \\
Output capacitor & $C_{o}$ & $20 \mu \mathrm{F}$ \\
Turns ratio & $N$ & 2 \\
Magnetizing inductance & $L_{m}$ & $5 \mathrm{mH}$ \\
Leakage inductance & $L_{k}$ & $5 \mu \mathrm{H}$ \\
\hline \hline
\end{tabular}

worst case scenario. So, after considering the aforementioned specifications, $L_{a}, L_{b}, L_{c}$ and $L_{d}=60 \mu \mathrm{H}$ is selected.

At Input side, decoupling capacitors $C_{1}$ and $C_{2}$ are chosen based on the fact that the maximum swing of voltage on $C_{1}$ and $C_{2}$ should be confined within the range 0 to $V_{C c}$. This constraint exists because the proposed converter is derived from the boost type differential converter which works on the principle that,

$$
0<v_{c 1}, v_{c 2}<V_{C c}
$$

As shown in the equations (17) and (18), the peak voltage of $v_{c 1}$ and $v_{c 2}$ may not only depends upon the peak of grid voltage but also on the peak of 2 nd harmonic voltage that is stored in the decoupling capacitors $C_{1}$ and $C_{2}$.

It is to note that this 2 nd harmonic voltage depends upon load parameters, i.e., output power and voltage, as can be seen in (21). Hence, $C_{1}$ and $C_{2}$ are selected considering the aforementioned constraints. Capacitance requirement at different turn ratio over wide battery voltage range can be determined by satisfying (31) using (23) or (24). The resulted graph is shown in Fig. 9. For the worst case battery voltage of $250 \mathrm{~V}$ and turns ratio $\mathrm{n}=2, C_{1}, C_{2}$ lies in the range of $80 \sim 100 \mu \mathrm{F}$. So, $100 \mu \mathrm{F}$ is selected.

Simulation waveform is shown in Fig. 10(a), it can be seen that a high power factor of 0.99 and input current $T H D_{i g}$ of $5.2 \%$ is achieved. DC battery current is obtained at the output which means that 2 nd harmonic component is successfully eliminated from the output current and is stored in the form of 2nd harmonic voltage component in the decoupling capacitors $C_{1}$ and $C_{2}$ as shown in Fig. 10(a).

The simulation waveform also shows that half of the switches of the proposed converter achieves ZVS Turn On during positive half cycle while other half of the switches achieve ZVS Turn On during negative half cycle. The extended waveform of the switches during $v_{g}<0$ is depicted in Fig. 10(b) which also shows that half of the switches are ZVS Turn on and half of the switches are Hard Turn On. So, during positive half cycle $S_{1}, S_{2}$, $S_{6}$ and $S_{8}$ can achieve ZVS Turn On while $S_{2}, S_{4}, S_{5}$ and $S_{6}$ are Hard Turn Off. On the other hand, during negative half cycle

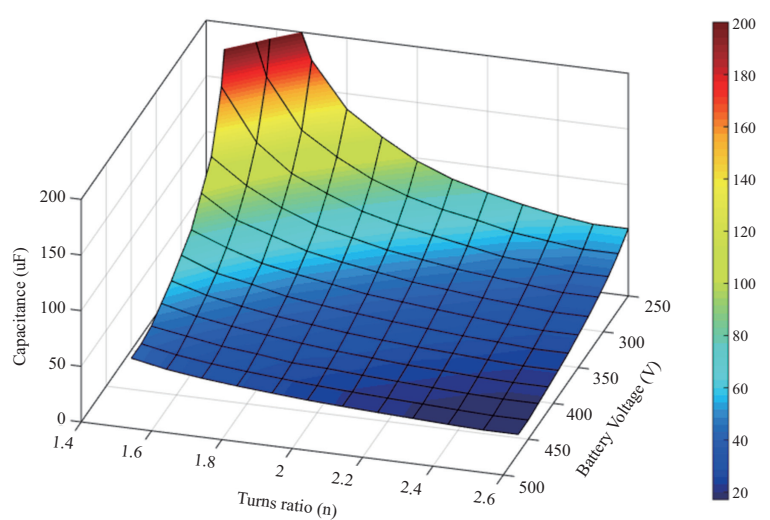

Fig. 9. Capacitance requirement for different turns ratio over wide output voltage range.

$S_{2}, S_{4}, S_{5}$ and $S_{6}$ can achieve ZVS Turn ON while $S_{1}, S_{2}, S_{6}$ and $S_{8}$ are Hard Turn Off. Note that all diodes at the secondary side achieve ZCS Turn Off due to clamping of $L_{k}$ with $C_{c}$ during the non-commutation mode of the transformer.

Two transformers of equal $L_{k}$ and $L_{m}$ are used for the simulation. For simulation, $L_{k}=5 \mu \mathrm{H}$ and $L_{m}=5 \mathrm{mH}$ is chosen and turn ratio $\mathrm{n}$ is selected as 2 . The simulation waveform of the transformer winding voltage for the grid frequency is shown in Fig. 10(c) and its FFT in Fig. 10(d).

A $6.6 \mathrm{~kW}$ experimental prototype is shown in Fig. 11. $1200 \mathrm{~V}$ Silicon Carbide switches are used at primary side of the converter and $650 \mathrm{~V} \mathrm{SiC} \mathrm{Schottky} \mathrm{diodes} \mathrm{are} \mathrm{used} \mathrm{for} \mathrm{secondary}$ side diodes. Two transformers are designed specifically for $200 \mathrm{kHz}$ to keep the size as compact as possible. The practical values of $L_{m}=4.7 \mathrm{mH}$ and $L_{k}=6.7 \mu \mathrm{H}$ for transformer 1 and $L_{m}=4.5 \mathrm{mH}$ and $L_{k}=6.3 \mu \mathrm{H}$ for transformer 2 are obtained with optimized design.

Fig. 12(a) shows the grid voltage and grid current obtained at around $2.2 \mathrm{~kW}$ power. It can be seen that a very high power factor of 0.99 with very low $T H D$ is achieved. After applying power decoupling control, pure DC voltage is obtained at the output and the 2nd harmonic power pulsation is store in the form of 2 nd harmonic voltage component in the input capacitors $C_{1}$ and $C_{2}$. The experimental waveform is illustrated in Fig. 12(b).

$L_{a}$ and $L_{b}$ are interleaved inductors with $180^{\circ}$ phase shift in switching frequency, similarly $L_{c}$ and $L_{d}$ are also interleaved. This phenomenon is experimentally illustrated in Fig. 12(c).

In this topology, high frequency transformers are utilized. The extended experimental waveform of transformer winding voltage and leakage current is presented in Fig. 12(d). It can be seen that the volt-sec of transformer winding voltage is balanced, therefore magnetizing current will not have any offset or low frequency component.

As already explained earlier, half of the switches achieve ZVS Turn ON during one half cycle and the other half of the switches achieve ZVS Turn ON during the other half cycle. The experimental waveform of this phenomenon for one leg switches is shown in Fig. 13. 


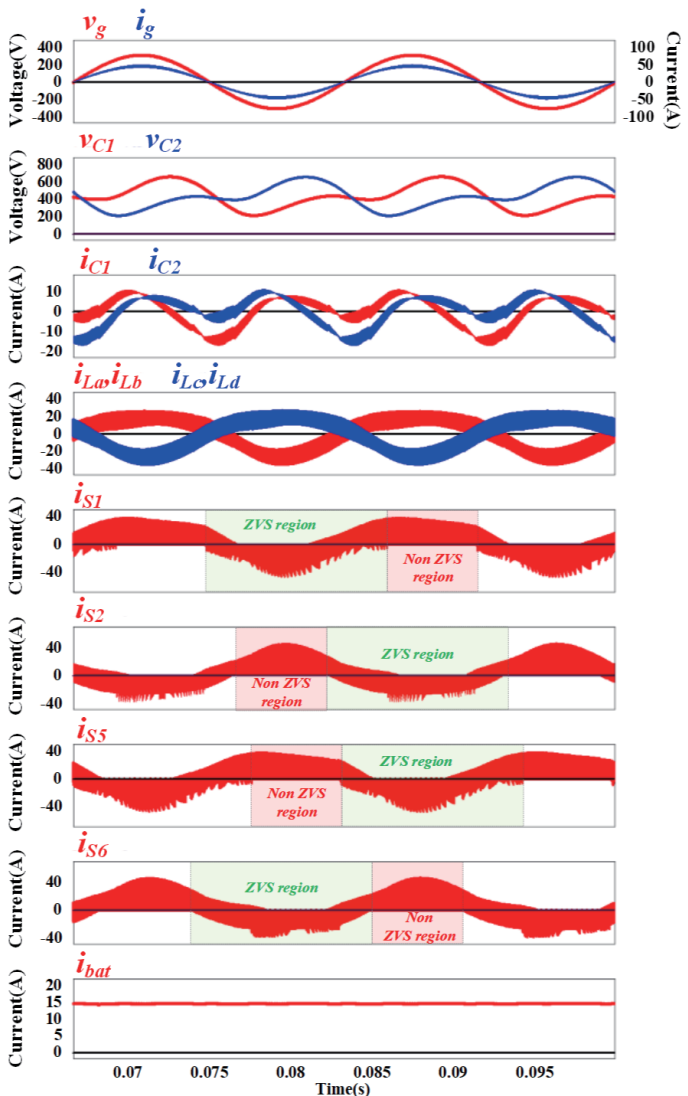

(a)

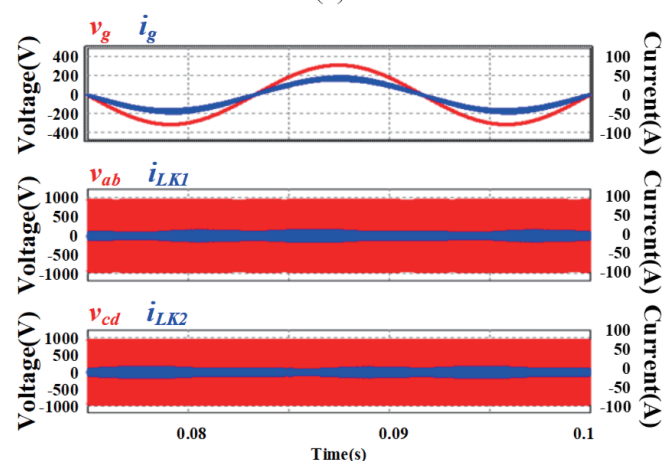

(c)
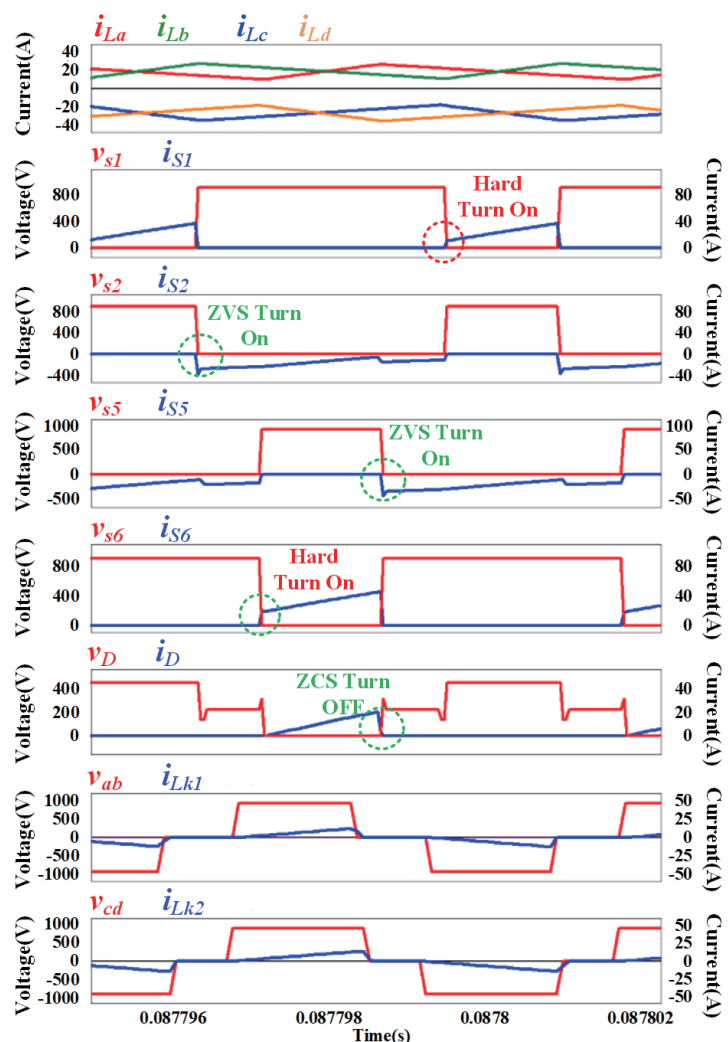

(b)

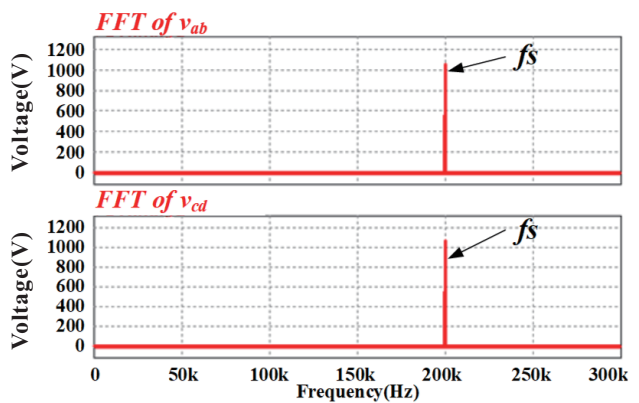

(d)

Fig. 10. Simulation waveforms. (a) Key waveforms of converter over line cycle. (b) Switch voltage and current over switching period. (c) Transformer winding voltage and current. (d) FFT of transformer voltage.

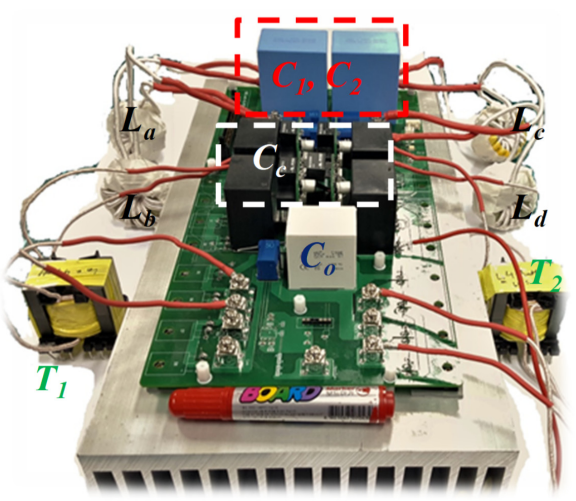

Fig. 11. Experimental prototype of proposed converter.

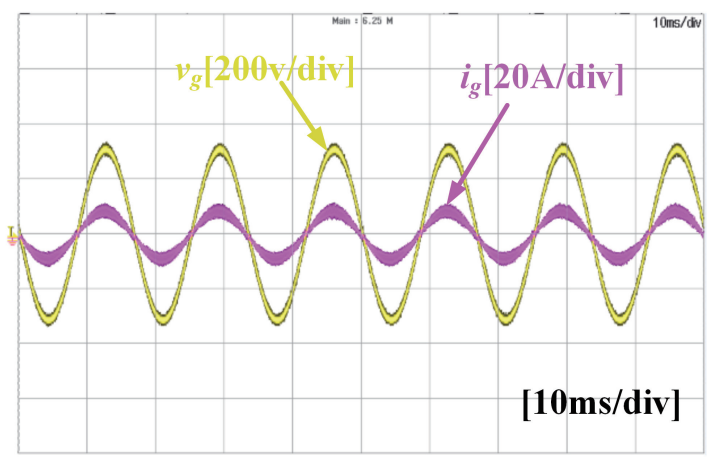

(a)

Fig. 12. Experimental waveforms. (a) Grid voltage $v_{g}$ and grid current $i_{g}$. 


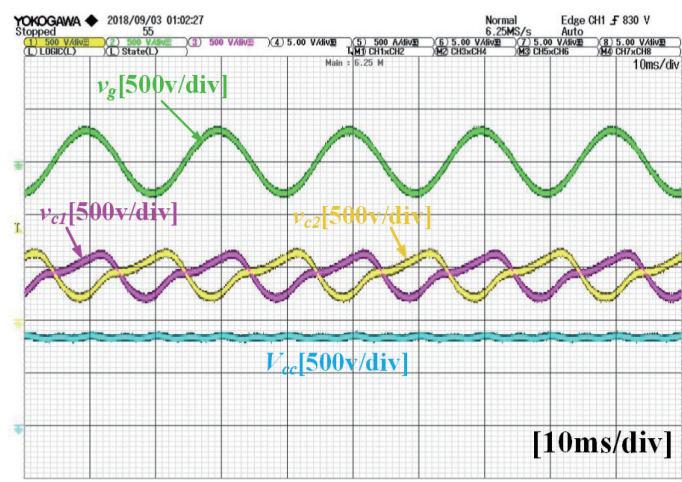

(b)

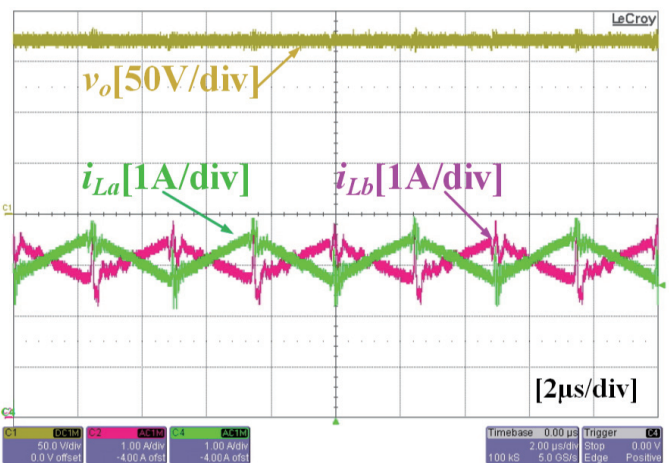

(c)

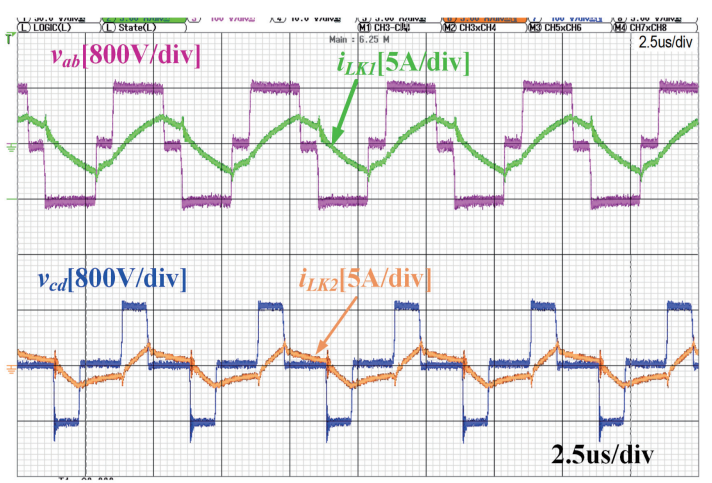

(d)

Fig. 12. (Continued..) Experimental waveforms. (b) Grid voltage $v_{g}$, decoupling capacitors voltage $v_{c 1}, v_{c 2}$ and clamping capacitor voltage $v_{C c}$. (c) Interleaved inductor current $i_{L a}, i_{L b}$ with output voltage $v_{o}$. (d) Transformer winding voltage and current.

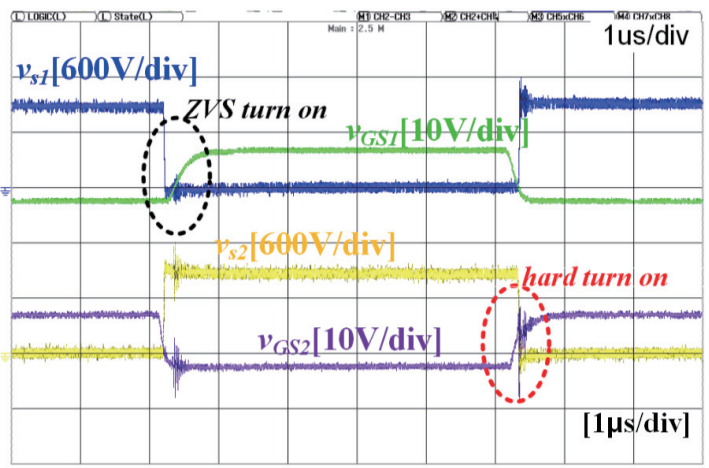

Fig. 13. Experimental waveforms of $v_{g s}$ and $v_{d s}$ of switch $S_{1}$ and $S_{2}$.

\section{CONCLUSION}

In this paper, a single-stage isolated AC-DC converter has been proposed for EV battery charger. The main features of the proposed converter include high-frequency isolation, and the AC-DC power conversion is done by a single-stage. AC power decoupling is successfully applied to obtain DC charging and the requirement to use bulky electrolytic capacitor is eliminated. Hence film capacitors with small capacitance can be used to enhance reliability and power density of the converter. One good feature of the proposed controller is that it does not require an on-line calculation based on complicated formulas to calculate reference voltage for shaping decoupling capacitor voltage. On the other hand, the switches are turned on with hard switched/ZVS in CCM which means half of the switches of this converter achieve ZVS Turn On during half line cycle and the other half of the switches are Hard Turn On. Moreover, all secondary diodes are turned Off with ZCS. Finally, a $6.6 \mathrm{~kW}$ prototype has been built and tested to verify the operating principles of the proposed onboard battery charger.

\section{REFERENCES}

[1] X. Zhang, D. Dome, and R. Rupp, "Efficiency improvement with silicon carbide based power modules", Power Electron. Europe, Issue 6, p. 27, Sept. 2009.

[2] H. Zhang, L. M. Tolbert, and B. Ozpineci, "Impact of SiC devices on hybrid electric and plug-in hybrid electric vehicles," IEEE Trans. Ind. Appl., vol. 47, no. 2, pp. 912-921, Mar.-Apr. 2011.

[3] A. Stippich, C.H. van der Broeck, A. Sewergin, A. H. Wienhausen, M. Neubert, P. Schulting, S. Taraborrelli, H. van Hoek, and R. W. De Doncker, "Key components of modular propulsion systems for next generation electric vehicles," CPSS Trans. Power Electron. Appl. vol. 2, no. 4, Dec. 2017.

[4] Department of Energy. EV everywhere: A grand challenge in plug-in, electric vehicles (initial framing document) (Aug. 2012) [Online]. Available: https://www.energy.gov/articles/ev-everywhere-wants-hear-all-you

[5] B. Singh, B. N. Singh, A. Chandra, K. Al-Haddad, A. Pandey, and D. P. Kothari, "A review of single-phase improved power quality AC-DC converters," IEEE Trans. Ind. Electron., vol. 50, no. 5, pp. 962-981, Oct. 2003.

[6] S. Gautam, F. Musavi, M. Edington, W. Eberle, and W. G. Dunford, "An automotive onboard 3.3-kW battery charger for PHEV application," IEEE Trans. Veh. Technol., vol. 61, no. 8, pp. 3466-3474, Oct. 2012.

[7] B. Whitaker et al., "A high-density, high-efficiency, isolated on-board vehicle battery charger utilizing silicon carbide power devices," IEEE Trans. Power Electron., vol. 29, no. 5, pp. 2606-2617, May 2014.

[8] S. Dusmez, X. Li, and B. Akin, "A fully integrated three-level isolated single-stage PFC converter," IEEE Trans. Power Electron., vol. 30, no. 4, pp. 2050-2062, Apr. 2015.

[9] B. Kim, M. Kim, and S. Choi, "A reduced component count single-stage electrolytic capacitor-less battery charger with sinusoidal charging," in 2017 IEEE 3rd Int, Future Energy Electron. Conf. ECCE Asia (IFEEC 2017 - ECCE Asia), Kaohsiung, 2017, pp. 242-246.

[10] B. Kim, M. Kim, and S. Choi, "Single-stage electrolytic capacitor-less AC-DC converter with high frequency isolation for EV charger," in 2016 IEEE 8th Int. Power Electron. Motion Control Conf. (IPEMC-ECCE Asia), Hefei, 2016, pp. 234-238.

[11] H. Belkamel, K. Hyungjin, K. Beywongwoo, Y. Shin, and S. Choi, "Bidirectional single-stage interleaved totem-pole AC-DC converter with high frequency isolation for on-board EV charger," in 2018 IEEE Energy Conv. Congr. Expo. (ECCE), Portland, OR, 2018, pp. 6721-6724.

[12] Y. Sun, Y. Liu, M. Su, W. Xiong and J. Yang, "Review of active power decoupling topologies in single-phase systems," IEEE Trans. Power 
Electron., vol. 31, no. 7, pp. 4778-4794, July 2016.

[13] K. A. Kim, Y. C. Liu, M. C. Chen, and H. J. Chiu, "Opening the box: survey of high power density inverter techniques from the little box challenge," CPSS Trans. Power Electron. Appl., vol. 2, no. 2, June 2017.

[14] P. T. Krein, R. S. Balog, and M. Mirjafari, "Minimum energy and capacitance requirements for single-phase inverters and rectifiers using a ripple port," IEEE Trans. Power Electron., vol. 27, no. 11, pp. 4690-4698, Nov., 2012.

[15] T. Shimizu, Y. Jin, and G. Kimura, "DC ripple current reduction on a single-phase PWM voltage-source rectifier," IEEE Trans. Ind. Appl., vol. 36, no. 4, pp. 1419-1429, Sep./Oct, 2000.

[16] L. Palma, "An active power filter for low frequency ripple current reduction in fuel cell applications," in Proc. IEEE SPEEDAM, Pisa, 2010. pp. $1308-1313$

[17] S. K. Mazumder, R. K. Burra, and K. Acharya, "A ripple-mitigating and energy-efficient fuel cell power-conditioning system," IEEE Trans. Power Electron., vol. 22, no. 4, pp. 1437-1452, July 2007.

[18] H. Han, Y. Liu, Y. Sun, M. Su, and W. Xiong, "Single-phase current source converter with power decoupling capability using a seriesconnected active buffer," IET Power Electron., vol. 8, no. 5, pp. 700-707, May 2015.

[19] R. Chen, Y. Liu, and F. Z. Peng, "DC capacitor-less inverter for singlephase power conversion with minimum voltage and current stress," IEEE Trans. Power Electron., vol. 30, no. 10, pp. 5499-5507, Oct. 2015.

[20] S. Fan, Y. Xue, and K. Zhang, "Novel active power decoupling method for single-phase photovoltaic or energy storage applications," in Proc. IEEE ECCE, Raleigh, 2012, pp. 2439-2446.

[21] W. Qi, H. Wang, X. Tan, G. Wang, and K. D. T. Ngo, "A novel active power decoupling single-phase PWM rectifier topology," in Proc. IEEE APEC, Fort Worth, TX, 2014. vol. 3, pp. 89-95.

[22] H. Zhao, H. Lin, C. Min, and K. Zhang, "A Modified single-phase H-bridge PWM rectifier with power decoupling," in Proc. IEEE IECON, Montreal, QC, 2012. pp. 80-85.

[23] I. Serban, "Power decoupling method for single-phase h-bridge inverters with no additional power electronics," IEEE Trans. Ind. Electron., vol. PP, no. 99, pp. 1, Feb. 2015.

[24] G. R. Zhu, S. C. Tan, Y. Chen, and C. K. Tse, "Mitigation of lowfrequency current ripple in fuel-cell inverter systems through waveform control," IEEE Trans. Power Electron., vol. 28, no. 2, pp. 779-792, Feb. 2013.

[25] S. Li, G. Zhu, S. C. Tan, and S. Y. Hui, "Direct AC/DC rectifier with mitigated low-frequency ripple through waveform control," in Proc. IEEE ECCE, Pittsburgh, PA, 2014. pp. 2691-2697.

[26] W. Yao, Y. Tang, X. Zhang, X. Wang, P. C. Loh and F. Blaabjerg, "Power decoupling method for single phase differential buck converter," in 2015 9th Int. Conf. Power Electron. ECCE Asia (ICPE-ECCE Asia), Seoul, 2015, pp. 2395-2402.

[27] W. Yao, X. Zhang, X. Wang, Y. Tang, P. C. Loh, and F. Blaabjerg, "Power decoupling with autonomous reference generation for single-phase differential inverters," in 2015 17th European Conf. Power Electron. Appl. (EPE'15 ECCE-Europe), Geneva, 2015, pp. 1-10.

[28] J. Almazan, N. Vazquez, C. Hernandez, J. Alvarez, and J. Arau, "A comparison between the buck, boost and buck-boost inverters," in 7th IEEE Int. Power Electron. Congr. Tech. Proc. CIEP 2000 (Cat. No.00TH8529), Acapulco, Mexico, 2000, pp. 341-346.
[29] A. Tausif and S. Choi, "Single-stage Differential Current-fed Isolated ACDC Converter for Electrolytic Capacitor-less OBC with DC Charging," in 2018 IEEE Int. Power Electron. Appl. Conf. Expo. (PEAC), Shenzhen, China, 2018, pp. 1-5.

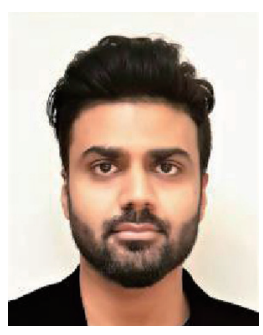

Ali Tausif was born in Pakistan, in 1991. He received his B.S. degree in Electrical Engineering from College of Electrical and Mechanical Engineering (CEME), National University of Science and Technology (NUST), Islamabad, Pakistan, in 2014. In 2016, he joined Power Electronics and Fuel Cell Power Conditioning Lab, SeoulTech as Graduate Research Student. He received his Master's degree from the Department of Electric and Information Engineering, Seoul National University of Science and Technology (Seoul Tech), in 2019. His research interests includes DC-DC converters and AC-DC converters for Electric Vehicles applications and Renewable Energy Systems.

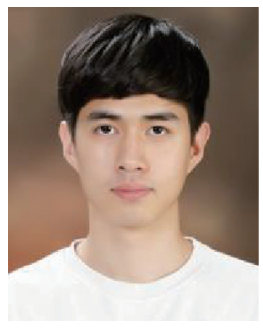

Hoyoung Jung was born in Korea, in 1992. He received the B.S. degrees in the Electrical and Information Engineering from Seoul National University of Science and Technology (Seoul Tech), Seoul, South Korea, in 2018, where he is currently working toward the M.S. degree in electrical and information engineering, Seoul Tech. His research interests include AC-DC converter and grid-connected inverter for electric vehicles and renewable energy systems.

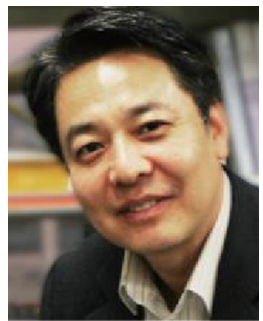

Sewan Choi received the B.S. degree in Electronic Engineering from Inha University, Incheon, Korea, in 1985 and the M.S. and Ph.D. degrees in Electrical Engineering from Texas A\&M University, College Station, TX, in 1992 and 1995, respectively. From 1985 to 1990 , he was with Daewoo Heavy Industries as a Research Engineer. From 1996 to 1997, he was a Principal Research Engineer at Samsung Electro-Mechanics Co., Korea. In 1997, he joined the Department of Electrical and Information Engineering, Seoul National University of Science and Technology (Seoul Tech), Seoul, Korea, where he is currently a Professor. His research interests include power conversion technologies for renewable energy systems and energy storage systems and DC-DC converters and battery chargers for electric vehicles. He is an associate editor of the IEEE Transactions on Power Electronics. He is an IEEE Fellow. 